UJBM, Vol. 2, No. 1, January - June 2003, pp 68-73

ISSN 0975-3311

https:/ / doi.org/ 10.12725/ ujbm.2.7

\title{
PERFORMANCE EVALUATION OF COLLEGE TEACHERS IN THE PRESENT SCENARIO
}

\author{
P.S.P. Swamy*
}

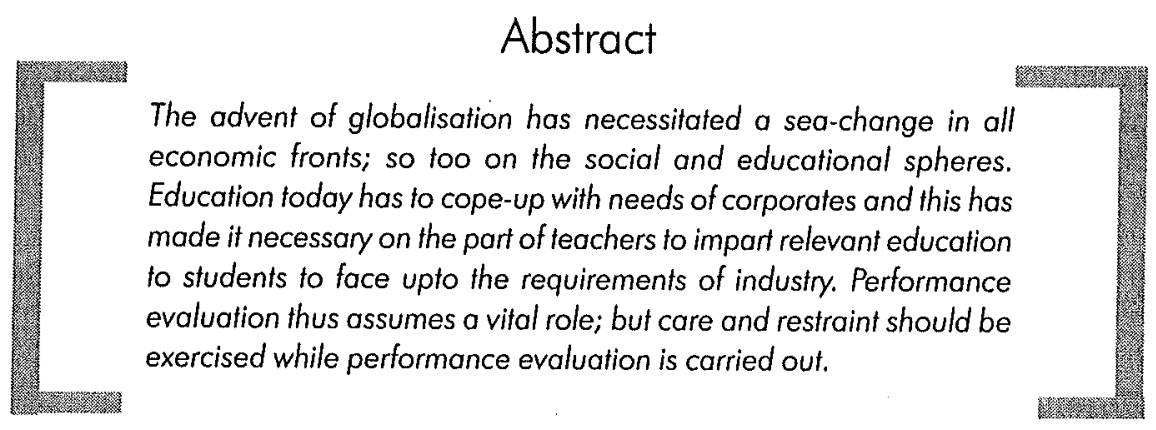

\section{Introduction}

At the outset, it is pertinent to know as to why there is a sudden spurt in the area of performance evaluation, especially for the teaching fraternity in general and college teachers in particular. Teaching has been considered as a noble profession from ages immemorial and teaching needed no evaluation, earlier, for there was little to evaluate.

*Lecturer in Commerce, A.P.S. College, Bangalore. 
Since the advent of globalisation, there have been metamorphical changes in the economic fronts. Economic impact, essentially as a by-product, has a social impact too, irrespective of whether one likes it or not. We now speak of trade across the countries and countries are now termed as global villages. Quality is not taken for granted by the customer. $\mathrm{He}$ expects $100 \%$ and nothing less. The same is true in the field of education. The studènt likes to have only the Best Education, which would enable him to face the stiff competition. One cannot continue to do what he has been doing in the past. One has to perform extremely well in order to attract the creamy layers and keep them constantly satisfied. Delivering mere paper qualification is not enough. It is time for the teachers to perform and impart quality education by improving quality of leaching. The expectation of students are high and, if unsatisfied, they will have lot of choices and will shift to another institution. For instance, it is not sufficient if we prepare our students to draft Trial Balance and Balance Sheets; instead they must acquire skills to analyse and interpret the Balance Sheet, by using appropriate ratios and other modern tools and techniques. They must have knowledge of using computer also. It is interesting to note that corporate houses have already entered this vibrant field either by starting their own institute or by partnering with existing institutes. Further, the Liberalization policy has led to "No students, No pay" and funds prioritization of primary education by World Bank are some of the factors.

\section{Need}

The need for job evaluation of teachers has taken its origin in business, where there is employee accountability to their superiors. It may be easy in case of a business but in case of teaching the problem assumes different dimension. For example, $\mathrm{Mr}$. $X$ is assembling components of $8,10,9,12$ every day. But on a particular day he turns out only 2 units. Whereas his counterparts have turned out 8 units. Immediately, there would be someone to evaluate as to why his performance was low on a particular day, or else, it would reach a stage where in nobody performs. Similarly in the education field there was a grave need for designing yardstick to evaluate teachers so as to derive accountability. Lately NAAC (National Accreditation and Assessment Council) keeps introduction of performance evaluation as one of the chief parameters for the award of its certification.

\section{Performance Evaluation of Teachers}

It is an appraisal system, which determines and measures the teachers performance in a systematic and objective manner and helps quality improvement in the education system. 


\section{Performance Indicators}

How to determine the quality of teachers? Is it at the input level or the output level? We have to try to evolve a rational approach in evaluating their standards. Before evaluating them one must give them the checklist of standards and specifications, which are generally acceptable. The teachers should know in advance as to what basis they have been evaluated on. It is normally on the basis of the following performance indicators for :

\section{a. Teachers}

1. Communication skill i.e. oral and writing.

2. Interaction with co-teachers, office staff and Principal / Boss.

3. Performance according to schedules.

4. Punctuality to class work.

5. Performance of employees on the job.

6. Interaction with students while also motivating them.

7. Extra curricular activities, such as writing articles in magazines and participation in various committees.

8. Honesty and integrity.

9. Research publications.

10. Assuming of responsibilities and its discharge.

11. Improvement in qualification and research work.

12. Results of students in tests and final examinations.

13. Moulding the all round personality of students.

14. Improvement in teaching methods and techniques.

b. For Principal the following are some of the parameters.

- Ability and willingness to delegate.

- Independent decision making ability and transparency.

- Relations with subordinates, students and public. 
- Facilities for all round development through extra-curricular activities.

- Encouragement for Innovation and Research facility.

- Leadership drive.

- Teaching skills.

- Planning and Administration and setting goals.

- Empathy and Social skills.

- Non-discrimination or equal treatment.

- Consideration for the weaker students and their performance.

- Regular conduct of meetings with the staff and implementation of outcomes.

- Concern for weaker sections of the society.

- Rewards and appreciation for performers.

- Learning mind, positive mental attitude.

Both the parties i.e. Management and Teachers must agree on some common terms. There should not be any scope for vagueness or ambiguity in describing the job. When once the measuring norms are accepted one should not dispute at the time of implementation.

\section{Precautions to be taken for deciding norms of measurement}

While performing evaluation, it is significant to note that it should not be at the input level but it should be necessary at the output level. For instance, a teacher may be punctual in going to the classes for 16 hours or recording the same in work diary or putting the second signature etc. But it is not the final yardstick to measure his performance. He might not have inspired the students in his subject. Instead, if tests were given to the students at a particular interval, it would be easy to judge the performance of teacher/trainer at the output level. This evaluation should be a continuous one and not a one shot business. Since we are dealing with human beings, objective measurement of teachers' performance is difficult if not impossible since we cannot fix any standard norms. In this context we should not expect $100 \%$ efficiency level but we must be satisfied by relative performance. In the light of this, forms must be circulated and the information collected from various sources and evaluated. 


\section{Methods of Evaluation}

There are basically five methods of evaluation namely :-

1. Self Evaluation : Evaluation made by the concerned staff member/teacher is the ideal one provided the institution has a positive work culture in the institution. Further the adage, "Business Management" is based on self management and Good Institutional Administration is based on "Self Administration."

2. Peer-to-Peer Evaluation : Wherein one teacher evaluates the performance of the other teacher. This would be practiced if there is an open culture in the institution and an ideal atmosphere around. If one peer gives a negative comment that person must be prepared to get the same coin in return from the affected peer.

3. Superior to Subordinate: Wherein the principal evaluates the performance of teachers in an Institute. He weighs the information collected from personal observation, students' responses and the entire system. In order to command respect from his subordinates the superior should be well versed in his line plus something more i.e. positive mental attitude. Further performance will be appraised and administered by Management and Director of Collegiate Education.

4. Subordinate to Superior : This method is quite popular in US and Germany and other European countries. Here teachers / students evaluate the performance of the principal. Principal is supposed to be the Focal Point, like the main spring of a watch. If such a method is adopted there would be dramatic changes and improvement in the organisation. The performance indicators of superiors are already given above.

5. Student Evaluation : In this process of collecting information from the students one may encounter the problem of biased and divided opinion. If that situation arises, one must be tactful and exercise a fair amount of judgement by giving the benefit to the teacher himself and preferably try to collect information from more than one source or sections and compare it with past years performance.

\section{Evaluation Report and Appraisal Strategy}

After collecting information, the next step is to analyse it and present the report to the employee. One should exercise tactfulness and shrewdness at this stage. 
1. This report should be given in the middle of the year so that an opportunity is given to the teacher for self improvement and not as a shock treatment at the end of the year or at the time of promotion / increment.

2. While passing on the feedback to the teacher one should present it on the basis of facts and not on the basis of personal judgement or some preconceived notion.

3. If one has to report negative points about a teacher he should prefer to include positive points also about the concerned teacher. First tell him all his positive points and then present his negative points.

4. One's objective should not be fault finding alone; instead one should analyse the various strengths and weaknesses of the teacher in a systematic and unbiased manner.

\section{Conclusion}

Performance evaluation of teacher in the present scenario is not an end in itself, but it is only a means for achieving quality improvement in the education system. Once the superior identifies the weaknesses of the concerned teacher he should not use this as a tool for punishment, it is his responsibility to provide him necessary facility for training and sufficient time and adequate scope for his intellectual improvement. The management should always strive hard to keep up the morale of teachers by positive ways by occasionally enquiring about their needs and address them to the extent possible. But at the same time to keep the customers comprising of students; parents and public at large delighted in the long run by taking appropriate steps in the right direction. 